\title{
Building to grow or growing to build: insights from Irish high-growth SMEs (HGSMEs)
}

Research Article

\author{
Rachel Kidney, Brian Harney* and Colm O'Gorman \\ Dublin City University, Dublin, Ireland
}

\begin{abstract}
Relative to the overall population of small- and medium-sized enterprises (SMEs), high-growth SMEs (HGSMEs) make a disproportionate contribution to economic growth. While research has identified factors that characterise HGSMEs, it is yet to provide a comprehensive explanation of the growth process. The purpose of the study is to identify specific growth events and examine how HGSMEs successfully transition through these periods in terms of operational (i.e. management systems and practices), structural, and strategic changes. Drawing from a descriptive profiling of Irish HGSMEs, four indepth case studies are presented. Analysis suggests a complex relationship between structure and growth, illuminating how HGSMEs experience trigger points that create a momentum of growth, which in turn mandates a supportive infrastructure.
\end{abstract}

Keywords: SMEs; high growth; growth processes; growth triggers

(C) De Gruyter Open Sp. z 0.0 .

\section{INTRODUCTION}

It is recognised that, relative to the population of small- and medium-sized enterprises (SMEs), high-growth SMEs (HGSMEs) make a disproportionate contribution to economic growth. HGSMEs are frequently cited by policymakers and idealised by entrepreneurs with growth ambitions (Volery et al., 2015). While extant research has identified factors that characterise HGSMEs, research has yet to provide a comprehensive explanation of the growth process. The objective of this paper is to extend this research by exploring triggers and transitions during specific highgrowth periods. In doing so, this study builds on Brown and Mawson's (2013) study of trigger points and high-growth firms (HGFs) by examining HGSMEs in an Irish context. Specifically, we present an in-depth case analysis of four Irish HGSMEs, examining the key events that triggered growth and, critically, how firms successfully transition through this period.

\section{CONTEXT: THE NATURE OF HGSME}

Research on indigenous HGSMEs remains extremely limited and tends to be characterised by anecdotes rather than a solid evidence base. Expansive research efforts documenting an aggregate profile of HGFs in England and Scotland offer some potential insights. Anyadike-Danes et al. (2009) examined firm growth, in terms of turnover and employment, over two 3-year periods, 2002-05 and 2005-08. HGFs represent roughly $6 \%$ of all UK firms employing $>10$ people (11,530 firms). While the majority of the firms are at least 5 years old, gazelles (i.e. firms in business for $<5$ years) grew faster and were responsible for a fifth of the employment growth generated by the population of HGFs. HGFs were spread across the major sectors, and almost half were located in the business services and the wholesale and retail sectors. The highest concentration of HGFs was in the financial services (9\%) 
and real estate and business service ( $8 \%$ ) sectors, while manufacturing had the lowest share (4\%). Geographically, HGFs were spread across the UK regions and particularly prevalent in South and East London, the UK's largest economic and commercial centre. In Scotland, Mason and Brown (2010) examined the turnover growth rate of all registered Scottish-based firms on the FAME database for the period 2006-09. In total, HGFs accounted for $4.1 \%$ ( 825 firms) of all Scottish-based firms employing $>10$ people, which is comparable to the results of research in Finland (Deschryvere, 2008) and Denmark (Peterson, 2006). Based on employment growth, the proportion of Scottish HGFs was identical to the UK national average in the period 2002-05 (6.3\%) and the highest regional area in the period 2005-08 (7\%; Anyadike-Danes et al., 2009). The majority (two-thirds) of Scottish HGFs were at least 15 years old and gazelles accounted for $<3 \%$ of the total high-growth population. Scottish HGFs were also found across major sectors, with more than one-third concentrated in the business services sector and the lowest share being in high-tech sectors (e.g. life sciences, energy). These findings lend support to the view of a more heterogeneous HGSME population, which extends well beyond high-tech, start-up gazelle-type enterprises (Mason and Brown, 2013).

\section{UNDERSTANDING THE GROWTH PROCESS}

Early life cycle theories of organisational growth suggest that companies move through predictable phases or stages of development that are path dependent (Churchill and Lewis, 1983; Greiner, 1972). Greiner proposes that growing firms move through five distinct phases characterised by the evolution of a specific management style, which is followed by a period of instability related to a specific management crisis. These development phases are believed to be path dependent (i.e. the cause and effect of the previous development phase). The logic underlying this argument is that a company's understanding of its present development phase and management history is necessary to anticipate and meet the needs of future phases. Similarly, Churchill and Lewis (1983) suggest that companies experience six stages of development characterised by an index of size, diversity, and complexity and described these in terms of five management factors focussing on skills required at each developmental stage. Life cycle theories have come under intense scrutiny from contemporary researchers, who claim that these models are too prescriptive and simplistic and thus do not accurately depict the development trajectory of a firm (Deakins and Freel, 1998; Levie and Hay, 1998; Levie and Lichtenstein, 2010; Phelps et al., 2007). Research using large-scale samples finds that firms do not necessarily develop based on a predictable sequence of stages but rather evolve through a series of stable and unstable states related to managerial problems (Levie and Hay, 1998). Similarly, Levie and Lichtenstein's (2010) analysis of research published between 1962 and 2006 found no empirical validation of stage theories. Others hold the view 'that stages occur sequentially and that all organisations follow that sequence is, at best, weak... a firm's growth is more complex, path dependent and unique to each firm, though encounters are recognisable as "tipping point" challenges' (Phelps et al., 2007: 4-8).

Over the past 3 decades, more process-focused models have emerged. These challenge the traditional life cycle assumptions that growth occurs as a linear sequence of predictive development stages. Deakins and Freel (1998) state that the growth process is often unpredictable and involves a number of disconnected jumps that result from a combination of knowledge and reactions to critical events. In a similar vein, Bessant and colleagues (Bessant et al., 2005; Phelps et al., 2007) suggest that growth is path dependent and a 'tipping point' or crisis is reached as a result of internal or external influences. These 'tipping points' can be resolved through the successful acquisition of new knowledge, which in turn allows further growth. These researchers also argue that path-dependent states appear at different points and may reappear later in a firm's development. More recently, Brown and Mawson (2013) propose that high-growth companies encounter growth triggers that act as catalysts that propel companies towards a period of rapid growth. Growth triggers can be changed as a result of external, internal, and co-determined actions (i.e. a combination of internal and external changes). These triggers are followed by a transition phase, which is defined as a period of instability and change. The successful management of the firm during this period determines the extent to which the growth opportunity is a success (Brown and Mawson, 2013). According to the authors, after the initial growth trigger, secondary triggers often emerge during these transition periods and can be equally, if not more, impactful on a firm's growth. Following the transition phase, firms are believed to experience a critical turning point in their business, which is defined by the beginning of a new growth phase. According to Brown and Mawson (2013), this process follows a temporal order such that the beginning of growth is marked by an initial growth trigger, followed by a transition phase, which in turn leads to a turning point in firm growth. 


\section{The determinants of growth in HGSMEs}

Growth is a challenging pursuit for SMEs as they are often resource constrained and lack managerial capabilities. Early adoption of new technologies, management systems, and structural reorganising to support growth is more prevalent in HGSMEs (Arbaugh and Camp, 2000; Davila et al., 2010; Julien, 2000). This infrastructure eliminates inefficiencies and co-ordinates resources to enable smooth transition through complex growth periods (Davila et al., 2010; Mazzarol et al., 2009). HGSMEs also stand apart from other firms in their resourcefulness and ability to improvise. Growth-oriented firms tend to acquire resources externally and/or apply recombinations of existing resources to opportunities and problems (Baker and Nelson, 2005). Moreover, HGSMEs make extensive use of business networks as a resource for learning and capability development (Barringer et al., 2005; Blundel, 2002; Hansen and Hamilton, 2011). Across studies, most HGSMEs have been shown to adopt some form of product, process, or service innovation (Blackburn et al., 2013; Hansen and Hamilton, 2011; Hilton and Hamilton, 2009). Barringer et al. (2005) have found that the strongest predictor of high growth is the creation of products and services that provide unique value to customers and attract high-quality channel partners. In terms of strategy, most HGSMEs adopt hybrid strategies (i.e. multiple strategic combinations). The most common is the pursuit of differentiation via innovation with some form of product customisation (Bamiatzi and Kirchmaier, 2014). An important feature of HGSMEs is their ability to professionalise while still retaining the benefits of being small by remaining flexible. According to Rindova and Kotha (2001), a key to strategic flexibility is the ability to reconfigure organisational arrangements (routines, structures, resources, and human/system capabilities) to support change.

It is clear that there are both theoretical and empirical deficiencies limiting our understanding of HGSMEs. Theoretically, literature has been subject to its own path dependency and has only recently begun to evolve beyond staged and life cycle approaches. Empirically, knowledge of HGSMEs has been deficient and distorted, with an emphasis on high-tech firms and a dominance of quantitative analysis (Henrekson and Johansson, 2009). Critical to advance understanding is further examination into the 'black box' of how HGSMEs manage critical growth transitions (Mason and Brown, 2013: 213). Based on existing research, and in particular Brown and Mawson's (2013) work on growth triggers in Scottish HGFs, we explore specific triggers that initiate the growth process and how firms manage their transition phase in terms of operational changes (i.e. management systems and practices), structure, and strategy.

\section{METHODOLOGY}

This paper draws on a broader research project, which adopts a mixed-methods approach to examine HGSMEs in Ireland. This approach enables simultaneous analysis of the process and outcome of high growth (Molina-Azorin et al., 2012). A key starting point involved identifying and profiling a sample of indigenous Irish HGSMEs from the FAME database for the period 2006-11. The FAME business database provides financial and non-financial information, such as age, size (in terms of employment and turnover), location, legal status, and sector of activity, on individual firms registered in the Republic of Ireland. In order to be included as an Irish HGSME, and following EU definitional criteria, three criteria had to be met; firms must have had turnover (revenue) of at least $€ 2$ million and no more than $€ 50$ million in the first observation period; second, they must employ a minimum of 10 and a maximum of 250 employees; and third, they must be independent, for-profit, and Irish-owned firms. High growth was measured based on turnover using the official Organisation for Economic Co-operation and Development (OECD, 2007) definition. Measuring growth in terms of turnover rather than employment has the advantage that turnover is less sensitive to capital intensity and applies to all firms irrespective of industry (Bamiatzi and Kirchmaier, 2014; Delmar et al., 2003; OECD, 2007).

Based on this SME criterion and high-growth definition, a sample of Irish HGSMEs was identified from the FAME database. Three discrete time periods were drawn from the FAME database (i.e. 2006-09, 2007-10, and 2008-11). Across these periods, an average of 1,035 SMEs was identified. After screening out subsidiaries and not-for-profit firms, a group of 45 HGSMEs emerged. The average age of the 45 Irish HGSMEs at the beginning of the observation period is 11.2 years. Gazelles (i.e. firms 5 years old or less) represent over a quarter of the total sample of HGSMEs. In terms of sector of activity, Irish HGSMEs are not confined to a particular sector but are concentrated in four sectors: manufacturing, information and communications, wholesale and retail trade, and professional, scientific, and technical activities (64\%). The remaining firms $(36 \%)$ are found across a further 10 
sectors. The majority of Irish HGSMEs (62\%) are clustered around the Dublin area, and the remaining ones are spread across Ireland. These findings broadly echo UK research (Mason and Brown, 2013).

Following detailed sampling, the second phase of the research involved in-depth case study analysis of four of these HGSMEs. The purpose of the case studies is to understand the formative changes that led to, or were required to support, the business through a phase of transition or change. The cases are based on semistructured interviews with the owner-manager or general manager to recount events associated with the period of high growth. The interviews are centred on significant events, or sequences of events (both internal and external), which led to, or were a consequence of, growth. To guide the enquiry, interview questions are based on a grid of strategic, operational (i.e. management systems and practices), and structural changes that may occur during the growth process. Archival data (e.g. company websites, newspaper articles, business publications, and financial data) is included to minimise social desirability bias, thereby enabling a more comprehensive analysis of HGSMEs.

The case firms are from different industries, including the oil and gas, plastics and packaging, software, and insurance and financial services. At the start of the observation period, three of these SMEs were of medium size and one was a small firm. For each of these companies, case descriptions were written based on available secondary data and combined with interview transcript themes that were identified across cases.

\section{RESULTS}

\section{The growth process in HGSMEs}

This section provides a general summary of four exemplary growth stories. Suretank is a global leading supplier of tank and containers to the oil and gas industries; OSG Outsource Services Group is a professional services provider to the insurance and financial services industry; and Ocuco is an optical software solutions supplier for optical retail chains and optical laboratory businesses worldwide. The fourth HGSME is a manufacturer and supplier in the plastics and packaging industry. The identity of this firm is withheld and will be identified as PlastiCo Ltd. This presentation is followed by a cross-case analysis to explore the growth process in Irish HGSMEs.

\section{Case study 1: Suretank}

Established in 1995, Suretank designs and manufactures specialist offshore tanks and containers for use by leading oil-producing, service, rental, and exploration companies. Suretank commands a $62 \%$ market share of a global customer base, with sales offices on every continent. Today, Suretank employs 635 people with turnover of $€ 71$ million. In the period $2008-11$, Suretank exhibited a $164 \%$ increase in turnover and $364 \%$ increase in employment.

A critical point in Suretank's growth came in 1999, with the expansion of its product range to manufacture containers designed to take waste products back from the drilling process. In order to navigate costs and labour shortages in Ireland, Suretank subcontracted with a Polish manufacturer to produce the new product, causing no strain on cash flow. As operations became more complex, Suretank hired a dedicated operations manager. With a foundation of capacity and organisation Suretank moved to find new businesses, including via acquisition of a UK factory, which enabled the introduction of carbon steel acid tanks and, in 2007, a move into Asia. At this time, Suretank also established regional sales offices in strategic locations around the globe.

In 2008 , Suretank suffered a $40 \%$ fall in revenues as a result of the oil price collapse and financial crisis. A successful turnaround was attributed to managing costs and driving its newly established sales division. The development of key markets also enabled the firm to spread risk, making them less vulnerable to local fluctuations. In 2010, business was getting 'chaotic' and a firm plan was needed to secure the company's future. Up until 2008-09, Suretank conducted business using Excel spread sheets, but the company was beginning to outgrow this method. In response, they invested in sophisticated systems for key functional areas (i.e. sales, production, and finance) to support the business.

\section{Case study 2: OSG Outsource Services Group}

OSG is a professional services provider that acts as a service layer between clients and their customers by offering a broad range of case management and ancillary services to deliver high-calibre cost-effective solutions. These include customer care services, loss adjusting, people learning and development, consulting, and 
recruitment placement. Its client base is located in Ireland and includes international insurance, banking and financial services, and the public sector. Clients include $>100$ blue chip companies, ranging from specialist companies to multinational organisations. In the period $2006-09$, turnover at OSG grew $77 \%$, while employment increased by $57 \%$.

OSG's roots are based in a loss adjustment partnership founded by Malcolm Hughes and partners in 1984, which quickly earned a reputation as a disruptive force in the Irish insurance industry. In 1997, the desire to scale led to the acceptance of an acquisition offer from Fishers International. The Irish operation proved a star performer in the Fisher portfolio, doubling turnover and profitability from 1997 to 2002 . However, financial issues at the parent company led to Malcolm Hughes and his Irish management team buying back the Irish company and making it private under the name OSG. This swift management by objectives (MBO) action ensured no threat to the company's reputation or loss of clients. Despite lucrative growth opportunities, OSG had to be prudent with finance as a result of the MBO. Short-term measures to reduce discretionary expenditure were supplemented by a company-wide plan to restructure costs, including elimination of redundancies, reducing natural wastage, and a $10 \%$ salary cut for all management and professional staff.

The OSG management was growing the business largely on its own resources and to exploit various opportunities, it was necessary to scale the company. In 2004, OSG began to carry out a number of acquisitions to gain additional business and people and to absorb competitors as a defensive strategy. They became cash generative and used this to refinance the company. Around this time, OSG also identified a need to diversify beyond the claims business to limit its dependency on any one area. A deliberate growth strategy was executed, which involved maintaining and developing existing relationships, selling different services, backing clients, and a move into other service areas and markets. These decisions coincided with substantial consolidation in financial services and an increased demand for outsourced services. OSG was able to take advantage of this trend supported by technological advancement, regulative changes, and a move to service the UK market. While this led to its most profitable period across 2008-09, it was also recognised that everything from the management infrastructure to offices began to 'creak at the seams'. A comprehensive strategic plan was initiated, introducing lean thinking and addressing the culture of OSG. This was credited with allowing OSG to grow while maintaining the entrepreneurial culture and agile business approach.

\section{Case study 3: Ocuco}

Established in 1993, Ocuco has grown to be a global market leader in the optics software industry and the second largest supplier worldwide, employing 110 skilled staff and generating a turnover of $€ 10$ million in 2012. Ocuco is a software solutions supplier to independents and large optical retail chains and optical laboratory businesses worldwide. These solutions include fully integrated optical practice and laboratory management systems, which enable the management of the entire process from marketing to order collection. With a global focus, Ocuco has offices in the UK, the USA, Canada, Australia, France, Spain, and Italy, serving a global customer base of $>5,000$ sites. Ocuco was the first in the market to offer a scalable management system to the optics market, which offers the most comprehensive, reliable, and flexible solutions to customers. Ocuco has the largest development team in the optical software industry and has invested $\$ 20$ million in research and development (R-and-D) to remain on the cutting edge of technology. In the 3-year period $2007-10$, Ocuco increased turnover by $78 \%$ and employment by $76 \%$.

Ocuco navigated a crisis period in 2001, marked by declining UK sales and the dot-com bust, which was perpetuated by the uncertainty brought about by $9 / 11$ terrorist attacks. Domestically, Ocuco suffered the impact of pharmacy deregulation and bad debts linked to a distributor. Another factor inhibiting its growth at the time was the lack of readiness of the market for its innovative optical software suite. Securing a big contract with Vision Express meant that its technologically superior and scalable software package obtained recognition. A consequence was a mass effort to ratchet up operations. Successful delivery provided a reference point that proved the viability of the integrated optical system. A decision was made to set the company up for growth founded on an MBO and an investment in infrastructure and scalable systems, e.g. a support help desk, a quality analysis department, a sales force automation system, a new human resources (HR) development manager, and upskilling of the professional services department and development team. Dependency on Vision Express was reduced, and the company grew organically and via strategic acquisitions, which enabled them to enter markets in the UK, France, and Italy. These geographical footprints supported the company in the global recession, coupled with business continuity strategies, including pay cuts, a focus on existing customers, and a big thrust to target smaller sales to independent stores. 


\section{Case study 4: PlastiCo}

Established in the early 2000s, PlastiCo designs, manufactures, and supplies foam and insulation products to the electronic, construction, and automotive industries. PlastiCo focusses on offering the best quality/price ratio, a high degree of responsiveness and flexibility, and multi-mixed product deliveries. PlastiCo has grown to become one of the largest manufacturers of plastics in Europe. Design and manufacturing facilities are located in Ireland and two in Poland, one of which is the largest in Europe. In meeting the criteria of consecutive growth over 2008-11, PlastiCo demonstrated an $81 \%$ growth in turnover and $64 \%$ growth in employment.

PlastiCo attributes its successful growth to financial strength, systematic reinvestment of profits into infrastructure, and commitment to innovation and quality. The essence of its success has been its vertically integrated business model, flexibility, and responsiveness. PlastiCo purposefully retains complete control of its production process and, as a result, employees have a reputation for in-depth technical knowledge across the business. This enables them to be more knowledgeable of customer needs and thus provides the best solutions to the exact specifications at a competitive price/value ratio. Initially, growth came from a contract to supply packaging to a leading personal computer (PC) manufacturer. Efficient production ensured that waste was recycled and reused for further production. In 2008, a decision was made to diversify its customer base, geographically with a move into the UK, as well as by supplying insulation to the construction and automotive industries. Growth was supported by the hiring of a sales manager with local and industry knowledge and further moves into Poland and France, each with clear objectives and targets. PlastiCo has successfully combined growth and stability, with the executive team remaining the same from the beginning, save for the addition of sales and production expertise.

\section{CASE ANALYSIS}

\section{External triggers and transitions}

Regulatory regime and market changes, both positive and negative, played an important role in growth. The case firms adopted an opportunistic approach to environmental change, and an ability to react quickly to exploit changing market demands has led to business survival and growth. Across the case companies, there were a number of reactive strategic decisions that demonstrate how opportunities were created from external changes and how the firms transitioned through challenges. For example, the European Union (EU) market regulatory changes affected the wider financial services and OSG's growth. Following the Irish financial crisis, tough regulations were sanctioned; however, OSG identified opportunities where others saw obstacles. Other important changes including technological advancements played a key role in supporting OSG's growth. For Suretank, the oil and gas industry has strict international safety standards. Suretank positioned itself as the safe choice in the market (i.e. 'engineering a better and safer future'). Its compliance with ongoing changes in international safety standards contributed to its reputation as a leader in safety standard accreditations.

Suretank operates a comprehensive and thorough quality control system... all equipment is built to international codes and standards and independently certified that is a very strong string in our bow (Michael Laverty, Sales Director, Sunday Business Post).

A number of medical legislative requirements were being established relating to information technology (IT), which had implications for Ocuco's ophthalmology business. The early response of Ocuco to incorporate additional features in its software enabled doctors to comply with legislation and made its product more attractive to customers. Similarly, the economic recession in the UK and Ireland proved lucrative for PlastiCo's business in the construction industry, by which sales of its economy product soared and became the product of choice on the market.

A characteristic common theme in Irish HGSMEs is their resilience in the face of regulation and market crises. All the case firms tended to create opportunities when challenges emerged in the market. In 2006, Suretank was operating in a booming oil industry - 'riding on the crest of the wave' - with facilities working at full capacity to meet product demand (Michael Laverty, Sales Director). However, the oil price collapse and financial crisis had a crippling effect on business. Suretank navigated through this by implementing strict cost-cutting strategies and accelerating its sales division. For Ocuco, a number of regulatory and market factors threatened its survival and growth. Early on, a failed UK market entry caused financial difficulty and forced two major decisions fundamental to its resilience. 
Ocuco diversified into the ophthalmology industry and extended sales to include small-scale sales to independent optical retailers, who were able to make smaller decisions and investments quickly. From here, they set out a strategy to invest in a new management board and set up the first scalable ophthalmology product. Later, in 2001, three major crises marked a difficult period: the 9/11 disaster and dot-com bust coincided with an overnight drop in UK sales from $€ 100,000$ to $€ 10,000$ a month. Though its presence in the Irish pharmacy market, along with the Euro currency changeover, enabled it to survive, deregulation of the market triggered a second crisis. This caused a collapse in sales and, at the same time, Ocuco's pharmacy distributor was declared unfit to pay its debts. According to Ocuco's chief executive officer (CEO), Leo MacCanna, another factor inhibiting growth was the lack of readiness of the market for its software suite:

These three crises left us in a lot of trouble and we had to come up with a turnaround plan... to cut costs and increase sales... Until now, the market wasn't interested in the scalable infrastructure we developed. However, in 2003, we got a contract with Vision Express that allowed us to prove our enterprise model...

This is when 'the sun came out', with turnover rising from $€ 1.4$ million in 2003 to $€ 4$ million in 2005 and marked the beginning of strategic decisions to stimulate further growth. This included using the success of the Vision Express contract as a global reference that demonstrated the quality of its product and investment in infrastructure to support the growing company.

\section{Firm-specific triggers and transitions}

Changes as a result of actions driven by Irish HGSMEs have played a significant role in stimulating business growth. In terms of the nature of these triggers, consistencies emerge across cases, including product development, acquisitions and diversification, management buy-out, and key hiring decisions. The expansion of HGSMEs' product portfolio and diversification into new product markets through product development and redesign have been significant in driving growth. Even during difficult periods, all HGSMEs reinvested the capital gained from sales in product and service development to grow their companies.

Suretank founder, Patrick Joy, refers to three strategies that help companies achieve growth quickly: the growth of existing business and product range into new geographical markets, development of new products, and acquisitions. Suretank's decision to expand its product portfolio to include containers was a critical trigger for growth. This was followed by a series of decisions, including the addition of a Polish subcontractor, the purchase of a new Irish production facility, the hiring of an operations manager, and a thrust in sales and marketing. The initial decision to expand its product range, coupled with additional support decisions, led to the growth in turnover from $€ 2.3$ to $€ 6.5$ million in 5 years. With reference to the Operations Manager, it was noted that:

He brought techniques to the shop floor, organised production in a formal way... before that there was no formal plan, nothing in writing... at the time we were very much a fire-fighting type of manufacturing organisation when he came in that made a big difference.

Similarly, OSG's strategy to continuously redesign solutions around changing market demands has enabled it to stay ahead of competitors by offering a growing portfolio of services tailored to customer needs. In PlastiCo's case, the development of a new product enabled it to move into the construction industry and a new geographic market, resulting in a sales surge during an economic recession, in which they were the product of choice in preference of industry alternatives. At the same time, the company hired a Sales Manager, who had the capabilities necessary to break into the new geographic and product market.

Acquisitions have been significant in driving the growth of Irish HGSMEs by enabling new market entry and diversification. These acquisitions provide access to local knowledge, capabilities in new product areas, an existing customer base, and a key route into national networks through established relationships. While diversification into markets helped HGSMEs to pursue further business opportunities, it also enabled these companies to avoid a dependency on a single market and customer base. An international presence also plays a key role in protecting companies from fluctuations in local markets and contributes to scaling for further growth.

To facilitate growth, Suretank acquired production facilities in the UK and China and has a $24 \%$ ownership in facilities in the US. This global reach allows Suretank to stretch out the risk by minimising vulnerability to changing demands in local markets and becoming closer to its international customers. OSG identified a need to diversify 
beyond its core business to avoid a dependency in any one area and developed a growth strategy to maintain and develop existing relationships and move into other markets and service areas. OSG conducted a number of acquisitions, one of which was a major competitor. The rationale behind these acquisitions was to scale the business by gaining additional customers and people resources, as well as a defensive strategy to absorb competitors. At one point, PlastiCo's main customer represented $90 \%$ of its business and the Irish packaging industry was becoming tough to compete in. The management became concerned with this dependency and diversified into related industries and geographical markets to widen its customer base and spread the risk. This saved the company as its major customer moved out of Ireland. At this time, PlastiCo also decided to set up additional facilities in Poland to serve its main customer. In doing so, it had proximity to the European market, access to a wider customer base, and expanded into other industries, which doubled turnover in 3 years.

Similarly, Ocuco's dependency on its major customer, which represented $75 \%$ of sales, preoccupied the management, which had a global vision for the company. As a result, the company pursued an aggressive acquisition strategy that gave access to different geographic markets and industries. In parallel, Ocuco was investing heavily in product redevelopment and rebranding. The acquisition of a UK optical retail company providing a dominant share in manufacturing and a US lens laboratory management systems company enabled access to local retail markets. These, in addition to other smaller acquisitions, doubled turnover in 2 years from $€ 4.2$ million in 2006 to $€ 8.4$ million in 2008. Further acquisitions in France and Italy gave entry into two key optical markets and a footprint in the Italian, Belgian, and Greek markets. Combined, these acquisitions ultimately saved the company in the face of an Irish recession, in which the optical market was struggling.

Two case studies refer to management buy-outs as affecting the course of their growth. Following a breakthrough contract, Ocuco was in a financial position to buy out investors. Ocuco set up an employee share distribution scheme and reinvested revenues to arrange an MBO that returned ownership to the CEO and Ocuco employees. With ownership reinstated, the management team set out to prepare the company for growth by investing in infrastructure. For OSG, financial problems in its public limited company (plc) presented an opportunity to buy back the company. However, the urgency with which the MBO needed to be carried out presented major financial difficulties. OSG transitioned through this period with no bank assistance by implementing various financial prudence strategies.

\section{The role of systems and structures in supporting growth}

Though systems supported business, earlier in the growth of these firms, it was often indicated that the case firms were not large enough to need or to invest in costly systems. The cases suggest that basic systems in functional areas were sufficient to support the business up to a point. This was typically at the later stages of the high-growth period when they began to outgrow existing systems. A number of the case firms stated that to exploit further opportunities, it was necessary to invest in an infrastructure that supported growth. Systems and structure appear to play a supportive role rather than as a driver of growth. The lack of scalable systems also created new problems for case firms and the need to develop a more sophisticated structure to meet the growing business demands. Suretank invested in systems to support functional areas in the middle-to-late stages of its high-growth period. The firm recognised a need to put a plan in place to secure the firm's future:

We were up to neck in muck and bullets trying to get drawings and designs done, products out and had sales guys out in the field asking for back-up and support. It was hectic... I was out leading the charge in sales and pulling everything from behind rather that having someone in the background with the skills and expertise to manage growth and control it by putting structures in place... That professionalization supported the growth without doubt (Patrick Joy, Suretank).

While the MBO at OSG resulted in a continuation of a successful business model, success in 2008-09 meant that things began to 'creak at the seams': office space was too small, IT systems were strained, the management infrastructure needed to be re-examined, and education and training needed to formalise. Rapid selection decisions were made to fit immediate needs and affected people quality and performance consistency. The biggest HR challenge was integrating a performance management system that aligned with a standard that the firm had a reputation for in the industry. For OSG, professional management systems in finance and operations were important for supporting its high growth. However, similar to Suretank, OSG's greatest challenge nearing the end of the highgrowth period was establishing consistency across systems rather than the layered approach that evolved during its growth, which resulted in an extra cost: 
It wasn't scalable or sustainable at that time because the systems weren't in place. There was less formality, less structure around how we did things but there was a growing need to put structures in place to grow it to the next stage (Malcolm Hughes, OSG).

Driven by this need, a strategic plan was put in place. Near the end of the high-growth period, a key decision to introduce a lean management programme helped correct existing systems that were operating independently. PlastiCo, a younger and smaller company, is characterised by a lack of formal systems and structures. This is largely attributed to its size, and spread sheets account for a lot of metrics and business monitoring. Though processes are in place, this evolved with growth rather than leading it:

We have a very rudimentary but effective system... it's not formal but it works. The value of that [structure and formality] is a matter of opinion. Formality applies as you become bigger and need formalities and systems in place as you grow because it's not possible to cope with everything hands on for the directors (General Manager).

At the beginning of the growth period, Ocuco invested in a scalable infrastructure. Following a growth in revenue and an MBO, Ocuco made a strategic decision to invest in scalable systems and structures to support growth into the international arena. This included the addition of a support help desk, a quality analysis department, a sales force automation system, a separate global sales force team, a new HR development manager, as well as upskilling of the professional services department and development team. At this time, Ocuco employed roughly 20 employees and did not require formal systems and structures up until its decision to scale the company for international growth.

Two major structural changes took place during Suretank's high growth. This involved the decision to develop a geographic structure, in the same way as its customers, and grow a more sophisticated sales structure by hiring regional sales offices in strategic locations. The purpose was to ensure the same product availability and the ability to work in the same timelines as customers around the globe. Nearing the end of its high growth, Suretank identified a need to put a professional structure in place, which was a key ingredient for escaping from day-to-day operations. This involved developing a formal management team, which included the hiring of new sales and finance directors. In addition, Suretank remodelled its engineering department into engineering for existing and future products. All of these decisions enabled Suretank to conduct business efficiently and professionally.

A common weakness across cases, according to the interviewees, is the lack of a formal HR structure during their high-growth period (cf. Harney and Dundon, 2006). OSG had a continuation of existing structures when it operated as a part of a plc and little change was experienced with the exception of a focussed investment in a formal HR function in the mid-to-late stages of high growth. This enabled OSG to monitor performance management and the selection process in a professionalised and formal way that aligned with its culture and objective. This included the introduction of formal training and induction processes, which replaced the 'quick fix - get them in, and get the job done' and 'sitting by nelly' training approach:

It was about the development of talent in a sophisticated way.... I personally wanted to communicate to OSG staff that this was our vision by actually doing it (CEO, Malcolm Hughes).

Like OSG, Suretank and PlastiCo did not have a formal HR structure and made bad selection decisions. PlastiCo directors encountered a management crisis at the beginning of the firm's growth. The firm hired a management team for a European subsidiary, entrusting the team with business decisions. In 2 years, the majority of the management team left to a competitor, causing a 'revolution'. In response, the directors secured assets and operations, relocated resources from Ireland to Europe, and employed new expertise from elsewhere in Europe.

\section{DISCUSSION}

\section{The nature of HGMSEs}

A comparison of the make-up of Irish HGSMEs and HGFs in Scotland (Mason and Brown, 2010) and England (Anyadike-Danes et al., 2009) reveal similarities across samples. The majority of the 45 Irish HGSMEs profiled from the FAME database are $>5$ years old, with one-quarter classified as gazelles; this contrasts with Scotland's $3 \%$ gazelles. In the UK, gazelles represent one-fifth of the employment growth generated by the population of HGFs 
(Anyadike-Danes et al., 2009). By comparison, Irish gazelles account for more than half of the turnover growth and one-third of the employment growth generated by HGSMEs. Over the high-growth period, Irish gazelles grow four times faster in terms of turnover and $20 \%$ faster in terms of employment compared to older HGSMEs. Similar to Scottish HGFs, on average, Irish HGSMEs tend to be younger, while high-impact companies are older. HGSMEs in Ireland are not confined to any one particular sector and are regionally concentrated around Dublin.

\section{Growth processes in HGSMES}

From the cross-case analysis, a consistent theme emerged regarding the nature of growth. The growth of case companies parallels the punctuated equilibrium path dependency theory proposed by life cycle models of growth (e.g. Churchill and Lewis, 1983; Greiner, 1972). However, the behaviour of the firms departs from the logic of life cycle theories as no evidence of a predictable linear stage pattern emerges across companies. Rather, growth in these cases is in accordance with Brown and Mawson's (2013: 6) model, which defines growth as a process with a temporal order, which 'comprises of an initial trigger point, followed by a transition phase, culminating in a critical turning point for the firm's development and growth potential'.

The growth of case companies is stimulated by significant external events and company-led strategic actions that thrust them towards growth or decline. The most prevalent external factors were regulatory regime and market changes, fluctuating economic conditions, and technological advancements. The case companies' reactive business decisions, resilience, and determination enabled them to exploit new opportunities and overcome challenges. Company-led changes such as product development and acquisitions enabled companies to diversify into different product and geographic markets. This made them less dependent on a single market and/or customer base and protected their business from local fluctuations. Management buy-outs, as well as key management and professional hires, also marked the start of a growth phase for some case companies. Key hires enabled access to new markets and professionalised the businesses in functional areas, enabling them to operate efficiently and thus maximise growth opportunities.

Across case companies, triggers were followed by a period of instability and change, resulting in problems and challenges to their existing operations (cf. Rumelt, 2011). As case companies reacted to specific triggers, this created complex challenges, precipitating a need to professionalise existing operations. In response, a cascade or sequence of changes in core functional areas occurred to support the growing business demands. This involved partnerships with subcontractors to provide additional resources, the expansion of company sales divisions to reach new customers, and adaptation of their strategic focus into different product and geographic markets. This behaviour parallels the logic proposed by Aldrich and Ruel (1999), who suggest that a contingent process of interaction between internal and external factors and actions affect growth. In a similar vein, Bessant et al. (2005) state that a 'tipping point' is reached as a consequence of internal or external influences that a firm must successfully resolve to continue to grow. There is also evidence of 'secondary triggers' across cases. Brown and Mawson (2013) argue that these emerge during transition periods as companies respond to an initial growth trigger. Following an initial growth trigger, case companies often changed their strategic focus and operational complexity. From this, further opportunities and/or challenges triggered a growth spurt and case companies faced the need to acquire or develop resources to deal with an emergent phase of instability.

In terms of systems and structures, case companies had a tendency to grow to a point where their systems are 'creaking at the seams' (OSG) or 'chaotic' (Suretank). Though advocated to play a supportive role by the interviewees in the cases, the development of systems and structure appear to lag behind growth. This was particularly evident for OSG and Suretank, whose existing systems and structures supported growth up until a point. Functional areas were developed independently to meet immediate business demands; however, at the later growth stages, case firms needed to revisit issues on a greater scale when they outgrew systems. This mirrors the path-dependent view of Phelps et al. (2007) that managerial problems can reappear at different points and Greiner's (1972: 401) explanation that:

New practices eventually sow their own seeds of decay and lead to another period of revolution. Companies therefore experience the irony of seeing a major solution in one time period become a major problem at a later state.

At the end of the high-growth period, a common characteristic across case companies was a clear strategic vision for future growth and investment in resources and capabilities, marking the beginning of a 'turning point' in firm development and a new growth phase. 
Research in the UK suggests that the characteristics of high-growth companies may be responsible for their resilience in tough times (Westlake et al., 2011). During high-growth periods, case companies exhibited reactive and proactive behaviours to exploit opportunities or protect the company from potential decline. Other characteristics that enabled firms to achieve growth include their ability to grow during external change and difficult competitive circumstances. This is attributed to their flexibility, resilience, and opportunism in the face of changing market conditions and recession. Interviewees indicate that their agility, flexibility, and entrepreneurial spirit are qualities that they intend to retain as they grow further. Case companies also appear to mirror UK HGFs in their sales focus. Brown and Mason (2010) found that HGFs in Scotland had a strong sales orientation, a clear vision, and a motivation to grow the company further. Moreover, Coad et al. (2012) suggest that UK HGFs tend to prioritise sales growth, and from this, employment, asset, and profit growth precipitate. The case companies in this study had a tendency to place sales as a strategic business priority, which led to employment expansion and growth in revenue. The case companies also identify HR as one of their greatest weaknesses during their high-growth period. This finding departs from that for Scottish HGFs, which are characterised by careful recruitment (Brown and Mason, 2010). The lack of a formal HR structure in terms of professionalised performance management systems and selection processes often led these companies into difficulties as a result of bad selection decisions and a lack of performance monitoring. However, these companies generally corrected these issues through the introduction of a formal HR function.

\section{Implications}

No previous study on Irish SMEs has defined high growth in terms of turnover. Thus, a major contribution of this research involves the identification of a sample of HGSMEs in Ireland, based on turnover, and providing a profile of this group. In doing so, the study demonstrates consistencies across Ireland and the UK in terms of common characteristics of high-growth companies. This study also extends research that examines triggers that lead to growth and how companies transition through significant growth periods (Brown and Mawson, 2013) by providing further evidence for the occurrence of this growth process. With respect to Irish policy and business support groups, our focus on HGSMEs provides Irish SMEs - with growth potential and aspirations - lessons on how to successfully manage challenges that arise with growth. These insights are of direct relevance to policy and SME stakeholders (cf. Ruane and Whelan, 2011), because 'while better management skills create business opportunities and support the development of best practices, many SMEs have relatively limited management capabilities, which need to be addressed' (National Competitiveness Council [NCC], 2011: 26). This is important as the SME sector is expected to play a vital role in fostering Ireland's economic renewal. This is largely because economies founded upon a large number of small firms are 'more flexible, innovative, competitive and less volatile' (Forfas, 2004: 3). In Ireland, this sector accounts for some $99.8 \%$ of enterprises, $69 \%$ of private sector employment, and $51 \%$ of gross value (Central Statistics Office [CSO], 2012). As such, the research provides policymakers and business support groups with a comprehensive understanding of the key characteristics of Irish HGSMEs. With this knowledge, policies and support can be tailored to fit SME needs and stimulate the Irish economy.

\section{Limitations and future research}

The findings of the first phase are limited by the availability of information on the FAME business database, which is a useful resource that has been used by a number of high-growth studies (e.g. Bamiatzi and Kirchmaier, 2014; Brown and Mawson, 2010; Coad et al., 2012). However, the sample drawn is based on SMEs that provide full turnover and employment data. ${ }^{1}$ As a consequence, an accurate HGSME population estimation could not be drawn for this research. Future research should explore alternative databases to access complete data to provide a profile of the population of Irish HGSMEs. Secondly, to analyse cases, this study adopted a mixed-method design and used multiple sources to comprehensively analyse the growth process. Future longitudinal research should track company growth as it happens. This would provide an opportunity to undertake in-depth analysis as events unfold.

\section{CONCLUSION}

To understand Irish HGSMEs, this study provided a profile of HGSMEs based on a sample of firms from the FAME business database, based on age, size, and growth rate, as well as location, legal form, and sector of activity. These firms were compared to the firms analysed by extensive research carried out in the UK, and striking similarities were 
identified across samples. Cross-case analysis of four firms identified in the first phase of the study was used to explore the growth process. The findings support previous research (e.g. Brown and Mawson, 2013) by providing evidence that the process of growth is characterised by triggers that create opportunities and challenges, followed by resource acquisition or development, to successfully transition through demanding periods. The ability or failure to adequately develop firm-level capabilities ultimately dictates the firm's growth or decline. It was also the case across firms that structure and systems formed more of a support for, rather than catalyst of, firm growth trajectories.

\section{ENDNOTE}

${ }^{1}$ In the FAME database, small companies often submit a short balance sheet and medium sized companies have no requirement to disclose turnover details until they grow to a certain point. A number of companies that did not submit complete turnover and employment data were removed from the sample'

\section{References}

Aldrich, H. E. and Ruel, M. (1999). Organizations Evolving, London: Sage.

Anyadike-Danes, M., Bonner, K., Hart, M. and Mason, C. (2009) Measuring Business Growth: High growth firms and their contribution to employment in the UK', London: NESTA, https://www.nesta. org.uk/sites/default/files/measuring_business_ growth.pdf

Arbaugh, J.B. and Camp, S.M. (2000). 'Sources of and responses to organizational complexity: $A$ comparison of growth-oriented and lifestyle firms', in P.D. Reynolds (ed.), Frontiers of Entrepreneurship Research, Wellesley, MA: Babson College, 612623.

Baker, T. and Nelson, R.E. (2005). 'Creating something from nothing: Resource construction through entrepreneurial bricolage'. Administrative Science Quarterly, 50: 1, 329-366.

Bamiatzi, V.C. and Kirchmaier, T. (2014). 'Strategies for superior performance under adverse conditions: A focus on small and medium-sized high growth firms'. International Small Business Journal, 32: 3, $\overline{259-284 .}$

Barringer, B.R., Jones, F.F. and Neubaum, D.O. (2005). 'Aquantitative content analysis of the characteristics of rapid-growth firms and their founders'. Journal of Business Venturing, 20: 1, 663-687.

Bessant, J., Phelps, R. and Adams, R. (2005). External Knowledge: A Review of the Literature Addressing the Role of External Knowledge and Expertise at Key Stages of Business Growth and Development, London: Advanced Institute of Management Research.

Blackburn, R.A., Hart, M. and Wainwright, T. (2013). 'Small business performance: Business, strategy, and owner-manager characteristics'. Journal of Small Business and Enterprise Development, 20: 1, 8-27.
Blundel, R. (2002). 'Network evolution and the growth of artisanal firms: A tale of two regional cheese makers'. Entrepreneurship and Regional Development, 14: 1, 1-99.

Brown, R. and Mawson, S. (2013). 'Trigger points and high growth firms: A conceptualisation and review of public policy implications'. Journal of Small Business and Enterprise Development, 20: 2, 179-255.

Central Statistics Office. (2012). Business in Ireland 2009, Discussion Paper, Dublin: Central Statistics Office.

Churchill, N. and Lewis, V. (1983). 'The five stages of small business growth'. Harvard Business Review, 61: 3, 30-50.

Coad, A., Cowling, M. and Siepel, J. (2012). Growth process of high growth firms in the UK, NESTA Report. London, UK.

Davila, A., Foster, G. and Jia, N. (2010). 'Building sustainable high growth startup companies: Management systems as an accelerator'. California Management Review, 52: 3, 79-105.

Deakins, D. and Freel, M. (1998). 'Entrepreneurial learning and the growth process in SMEs'. The Learning Organisation, 5: 3, 144-155.

Delmar, F., Davidsson, P. and Gartner, W.B. (2003). 'Arriving at the high growth firm'. Journal of Business Venturing, 18, 189-216.

Deschryvere, M. (2008). High growth firms and job creation in Finland, Working Paper 1144, Helsinki: Research Institute of the Finnish Economy.

Forfas. (2004). Market, Innovate, Sell: Sales, Marketing and Innovation Capabilities of Irish Exporting SMEs, Dublin: Forfas.

Greiner, L.E. (1972). 'Evolution and revolution as organizations grow'. Harvard Business Review, 50, 37-46.

Hansen, B. and Hamilton, R.T. (2011). 'Factors distinguishing small firm growers and non-growers'. 
International Small Business Journal, 29: 3, 278294.

Harney, B. and Dundon, T. (2006). 'Capturing complexity: Developing an integrated approach to analysing HRM in SMEs'. Human Resource Management Journal, 16: 1, 48-73.

Henrekson, M. and Johansson, D. (2009). 'Competences and institutions fostering high-growth firms'. Foundations and Trends in Entrepreneurship, 5: 1, $1-80$.

Hilton, M. and Hamilton, R.T. (2009). Kiwis that Fly: High Growth Businesses in New Zealand, Paper to the 32nd ISBE Conference, 3-6 November, Liverpool.

Julien, P.A. (2000). 'High growth SMEs: Explanatory factors'. Investigaciones Europeas de Direccion y Economia de la Empresa, 6: 2, 39-56.

Levie, J. and Hay, M. (1998). Progress or Just Proliferation? A Historical Review of Stages Models of Early Corporate Growth, London Business School, Working Paper.

Levie, J. and Lichtenstein, B.B. (2010). 'A terminal assessment of stages theory: Introducing a dynamic states approach to entrepreneurship'. Entrepreneurship Theory and Practice, March, 317-350.

Mason, C. and Brown, R. (2010). High Growth Firms in Scotland, Glasgow, Scotland, UK: Scottish Enterprise.

Mason, C. and Brown, R. (2013). 'Creating good public policy to support high-growth firms'. Small Business Economics, 40: 2, 211-225.

Mazzarol, T., Reboud, S. and Soutar, G.N. (2009). 'Strategic planning in growth oriented small firms'. International Journal of Entrepreneurial Behaviour and Research, 15: 4, 320-345.

Molina-Azorin, J., Lopez-Gamero, M., Pereira-Moliner, J. and Pertusa-Ortega, E. (2012). 'Mixed methods studies in entrepreneurship research: Applications and contributions'. Entrepreneurship and Regional Development, 24: 5-6, 425-456.

National Competitiveness Council. (2011). Ireland's Competitiveness Scorecard, Dublin: National Competitiveness Council, July.

OECD. (2007). High Growth Enterprises and Gazelles, Paris: OECD.

OECD. (2010). High Growth Enterprises: What Governments Can Do to Make a Difference, Paris: OECD.

Peterson, D.R. (2006). High Growth Firms and Gazelles in Denmark, FORA, http://slideplayer.com/ slide/3794699/

Phelps, R., Adams, R. and Bessant, J. (2007). 'Life cycles of growing organisations: A review with implications for knowledge and learning'. International Journal of Management Review, 2: 1, 1-30.

Rindova, V.P. and Kotha, S. (2001). 'Continuous 'morphing': Competing through dynamic capabilities, form, and function'. Academy of Management Journal, 44: 6, 1263-1280.

Ruane, F. and Whelan, B. (2011). 'Building research capacity in the social sciences alternatives approaches'. Journal of the Statistical and Social Inquiry Society of Ireland, XL, 133-151.

Rumelt, R. (2011). Good Strategy/Bad Strategy: The Difference and Why It Matters, London: Profile Books.

Volery, T., Mueller, S. and von Siemens, B. (2015). 'Entrepreneur ambidexterity:Astudy of entrepreneur behaviours and competencies in growth-oriented small and medium-sized enterprises'. International Small Business Journal, 33: 2, 109-129.

Westlake, S., Marston, L. and Bravo Biosca, A. (2011). Vital Growth: The Importance of High Growth Business to the Recovery, NESTA Report. 